\title{
Assessment of Nurses' Knowledge about Ethical and Legal Issues in Mental Health Nursing at Psychiatric Teaching Hospitals in Baghdad City
}

\author{
Qahtan Q. Mohammed, PhD ${ }^{1}$, Enas H. Mohammed ${ }^{2}$, Maisam H. Karim ${ }^{3}$, Noor \\ A. $\operatorname{Hassan}^{4}$ \\ ${ }^{\text {I}(I n s t r u c t o r, ~ P s y c h i a t r i c ~ M e n t a l ~ H e a l t h ~ N u r s i n g, ~ C o l l e g e ~ o f ~ N u r s i n g, ~ U n i v e r s i t y ~ o f ~ B a g h d a d, ~ I r a q) ~}$ \\ ${ }^{2}$ (College of Nursing, University of Baghdad, Iraq) \\ ${ }^{3}$ (College of Nursing, University of Baghdad, Iraq) \\ ${ }^{4}$ (College of Nursing, University of Baghdad, Iraq)
}

\begin{abstract}
Objectives: The study aims to assess nurses' knowledge about ethical and legal issues in mental health nursing at psychiatric teaching hospitals in Baghdad City; and to identify the relationship between nurses' knowledge and some of their characteristics such as: gender, age, nursing qualification, marital status, and years of clinical experience.

Methodology: A descriptive analytical study in which assessment approach is applied in order to achieve the earlier stated objective the study was initiated from November 1, 2016 to may 1, 2017. A purposive (nonprobable) sample of 100 nurses who are working at psychiatric wards. Data were collected through the use of the questionnaire and the process of the self-administrative report as means for data collection. Data were analyzed through the application of descriptive and inferential statistical approaches by using statistical package for social science (SPSS) version 20.0.

Results: The finding of the study revealed that most of the nurses how are working at psychiatric wards were female with age 20-30 years old and graduated from medical institute. The nurses have more than five years of experience in nursing and psychiatric nursing and working at wards. The nurses have good knowledge about legal issues in mental health nursing. The nurses have good knowledge about ethical issues in mental health nursing. There is no significant relationship between nurses' knowledge about legal and ethical issues respect to their age, gender, qualification, marital status and years of experience.

Conclusions: The study concluded that nurses have good knowledge about legal issues and ethical issues in mental health nursing and there is no significant relationship between nurses' with respect to their age, gender, qualification, marital status and years of experience.

Recommendations: The study recommended providing training courses for nurses who are working at psychiatric units to increase their practices about ethical and legal issues in such setting. The booklet of (legal and ethical issues in mental health nursing) should be distributed for newly recruited nurses in psychiatric hospitals and wards.
\end{abstract}

Keywords: Nurses' Knowledge, Ethical issues, Legal issues, Mental Health Nursing

\section{Introduction}

Legal and ethical issues for psychiatric nursing profession is an important topic just like scientific issues, for this reason nursing profession should have its own professional ethics and laws ${ }^{(1)}$.

Understanding the ethical and legal issues is an important for nurses who are working at psychiatric department, by which they can get the power of influence in daily disquisition while they dealing with psychiatric patients ${ }^{(2)}$.

The world Health Organization has stressed the need to create rules for the legal and ethical issues in nursing profession, and from there came the idea for preparing a special system specialized in the legal and ethical behavior of the nursing staff working in the psychiatric hospitals and mental health centers, containing all the basic principles that the psychiatric nurses depend on when dealing with the mentally ill patients ${ }^{(1)}$. A dynamic relationship has been known among the concepts of mental illnesses, psychiatric treatment, ethical and legal issues in psychiatric nursing ${ }^{(3)}$.

The ethical aspect deals with standards of conduct and moral judgment. The main principles of health care ethics that must be supported in all cases are beneficence, autonomy and justice. While the legal issue is defines as those that the nurse must obey as a law in a professional way or the activities of psychiatric nurses legally allowed with the care of patients with mental illness ${ }^{(4)}$. 
The health care system composed of multidisciplinary groups with different professions, the nurses are one of the most important groups that are working in this health care system and provide health care services in different setting and their presence is very important for completion of the other groups in health care system. The nurses who working at psychiatric nursing department have many duties and responsibilities to do; they have an important role in admitting the patients and doing a psychiatric assessment and provide support for the patients and family, and also maintain the privacy and confidentiality of psychiatric patients. In addition to these responsibilities, the psychiatric nurses other duties that are related to legal and issues of the patients such as admission and discharge, explaining the rights of the patients, taking informed consent and other related issues, all come under legal and ethical responsibilities of a psychiatric nurse, therefore, the psychiatric patients should have adequate knowledge and practices regarding ethical and legal issues ${ }^{(3)}$.

In this study the researcher are trying to explore to which extent that psychiatric nurses have knowledge about ethical and legal issues that are important in dealing with psychiatric patients considering as an principal part of nursing process in psychiatric mental health nursing.

The study aims at:

\section{Oblectives Of The Study}

(1) Assessing nurses' knowledge about ethical and legal issues in mental health nursing at psychiatric teaching hospitals in Baghdad City.

(2) Identifying the relationship between nurses' knowledge and some of their characteristics such as: gender, age, nursing qualification, marital status, and years of clinical experience.

\section{Methodology}

Design of the Study: A descriptive analytic study, an assessment approach has been applied for the purpose of achieving the earlier stated objective. The study was initiated from November 1, 2016 to May 1, 2017.

Administrative Arrangements: The permission has been granted from Ministry of Health /Medical City Directorate and Al Rusafa Health Directorate and Al Karkh Health Directorate. These consents facilitated the researchers' entrance to the hospitals and meeting the nurses.

Ethical Consideration: The first ethical consideration was approved by the Ethical Committee in the College of Nursing, University of Baghdad on the study questionnaire; the second ethical consideration was related to agreement of nurses for participation in this study.

Setting of the Study: The study has been conducted on the nurses who are working at psychiatric wards and hospitals in four hospitals in Baghdad which are: Baghdad Teaching Hospitals /Medical City Directorate and Ibn Rushd Teaching Hospital and Al Rashad Teaching Hospital /Al Rusafa Health Directorate and Al Jawadain Medical City /Al Karkh Health Directorate.

Sample of the Study: A purposive (non- probability) sample of 100 nurses was selected from nurses' staff who are working at psychiatric wards and hospitals.

Instrument of the Study: Self administrative questionnaire was conducted by the investigators for the present study through review of available literature ${ }^{(4)}$ and the related previous studies scale ${ }^{(3)}$. The constructed questionnaire consisted of three parts: the first part contained the covering letter to obtain nurses agreement to participate in the study and socio - demographic characteristic of nurses; the second contained 20 items that measure nurses' knowledge about ethical issues; and the third part contained 20 items to measure nurses' knowledge about legal issues in mental health nursing. These items were rated to three level of Likert scale and scored the follows: I know (3), not sure (2), I don't know (1). The levels of nurses' knowledge were determined by calculating the ranging score for the total score of the scale, which divided into three levels as rated: Poor $=$ $20-33$, Fair $=34-47$, and Good $=48-60$. These levels were calculated for both scales; nurses' knowledge about legal issues and nurses' knowledge about ethical issues.

Validity of Questionnaire: Content validity for the instrument was determined through the use of panel experts to investigate the clarity, relevancy, and adequacy of the questionnaire in order to achieve the present study objectives. In addition to the experts' responses, their suggestions were taken into consideration. So far, modifications were employed and the final copy of the constructed instrument was completed to be an appropriate tool for conducting study.

Pilot Study: A pilot study was carried out for the period from December $1^{\text {st }}, 2016$ to December $30^{\text {th }}, 2016$ and conducted on 20 subjects.

Reliability of the Questionnaire: The internal consistency of the instrument was determined through the pilot study and the computation of alpha correlation coefficient (cronbachś alpha). The result of the reliability was $(\mathrm{r}=0.81)$ and such an estimation was statistically adequate which means that the questionnaire had adequate level of internal consistency and equivalence measurability.

Data Collection: The data have been collected through the utilization of the self administrative questionnaire as a means of data collection. Self administrative questionnaire was distributed to nurses working in mental health 
settings after being willing to answer the questionnaire and participate in the study; all of the respondents were cooperative with the investigators .filling the questionnaire takes approximately 15-30 minutes.

Data Analysis: Statistical analyses were conducted by using statistical package for social science (IBM SPSS) version 20.0. Data analysis was employed through the application of descriptive and inferential statistical approaches.

\section{Results}

Table (1) Demographic Characteristics of Nurses

\begin{tabular}{|c|c|c|c|c|}
\hline No. & Characteristics & & $\mathbf{F}$ & $\%$ \\
\hline \multirow[t]{3}{*}{1} & \multirow[t]{3}{*}{ Gender: } & Male & 48 & 48 \\
\hline & & Female & 52 & 52 \\
\hline & & Total & 100 & 100 \\
\hline \multirow[t]{6}{*}{2} & \multirow[t]{6}{*}{ Age group: } & $\leq 19$ years & 1 & 1 \\
\hline & & $20-29$ years & 37 & 37 \\
\hline & & $30-39$ years & 37 & 37 \\
\hline & & $40-49$ years & 15 & 15 \\
\hline & & $50 \leq$ years & 10 & 10 \\
\hline & & Total & 100 & 100 \\
\hline \multirow[t]{5}{*}{3} & \multirow[t]{5}{*}{ Qualification: } & Nursing school & 39 & 39 \\
\hline & & Medical Institute & 35 & 35 \\
\hline & & Nursing College & 21 & 21 \\
\hline & & Higher education & 5 & 5 \\
\hline & & Total & 100 & 100 \\
\hline \multirow[t]{3}{*}{4} & \multirow[t]{3}{*}{ Marital status: } & Unmarried & 32 & 32 \\
\hline & & Married & 68 & 68 \\
\hline & & Total & 100 & 100 \\
\hline \multirow[t]{3}{*}{4} & \multirow[t]{3}{*}{ Marital status: } & Unmarried & 32 & 32 \\
\hline & & Married & 68 & 68 \\
\hline & & Total & 100 & 100 \\
\hline \multirow[t]{3}{*}{5} & \multirow[t]{3}{*}{ Years of clinical experience: } & $<5$ years & 43 & 43 \\
\hline & & $>5$ years & 57 & 57 \\
\hline & & Total & 100 & 100 \\
\hline \multirow[t]{3}{*}{6} & \multirow{3}{*}{$\begin{array}{l}\text { Years of experience in } \\
\text { psychiatric }\end{array}$} & $<5$ years & 67 & 67 \\
\hline & & $>5$ years & 33 & 33 \\
\hline & & Total & 100 & 100 \\
\hline \multirow[t]{3}{*}{7} & \multirow{3}{*}{$\begin{array}{lll}\text { Reviewing } & \text { Iraqi } & \text { Mental } \\
\text { Health Act: } & & \end{array}$} & Yes & 32 & 32 \\
\hline & & No & 68 & 68 \\
\hline & & Total & 100 & 100 \\
\hline \multirow[t]{3}{*}{8} & \multirow[t]{3}{*}{ Reviewing code of ethics: } & Yes & 68 & 68 \\
\hline & & No & 32 & 32 \\
\hline & & Total & 100 & 100 \\
\hline
\end{tabular}

No: Number, F: Frequency, \%: Percentage

The analysis of this table shows that female nurses are more than male nurses that are working at psychiatric hospitals (52\%). Their age group shows that the highest percentage is distributed between twenties and thirties (37\%). 39\% of nurses are graduated from nursing school and 35\% of them are graduated from medical institution. Regarding marital status, more than half of them are married (68\%). 57\% of nurses are working in nursing field for a period more than five years (57\%). $67 \%$ of them are working in psychiatric nursing for a less than five years. Only $32 \%$ of them were reviewing the Iraqi Mental health Act and know about it, while $68 \%$ of them were aware of Code of Ethics for Iraqi Nurses and Midwifery.

Table (2) Nurses' Knowledge about Legal Issues in Mental Health Nursing

\begin{tabular}{|c|c|c|c|c|}
\hline Knowledge & F & \% & M & SD \\
\hline Poor & 0 & 0 & \multirow{2}{*}{2.71} & \multirow{2}{*}{0.456} \\
\hline Fair & 29 & 29 & \\
\hline Good & 71 & 71 & & \\
\hline
\end{tabular}

F: Frequency, \%: Percentage, M: Mean, SD: Standard Deviation

This table indicates that nurses at psychiatric hospitals have good level of knowledge about legal issues in mental health nursing (71\%) and only $29 \%$ showing a fair level of knowledge. 
Table (3) Nurses' Knowledge about Ethical Issues in Mental Health Nursing

\begin{tabular}{|c|c|c|c|c|}
\hline Knowledge & F & \% & M & \\
Poor & 0 & 0 & \multirow{2}{*}{2.96} & 0.197 \\
\hline Fair & 4 & 4 & \\
\cline { 1 - 3 } Good & 96 & 96 & & \\
\hline
\end{tabular}

F: Frequency, \%: Percentage, M: Mean, SD: Standard Deviation

This table reveals that most of psychiatric nurses are showing a good level of knowledge about ethical issues in mental health nursing (96\%) and only $4 \%$ of them are showing fair knowledge.

Table (4) The Relationship between Nurses' Knowledge about Legal Issues with their Socio-demographic Characteristics $(\mathrm{N}=100)$

\begin{tabular}{|l|c|c|c|c|}
\hline Knowledge & Chi-square & d.f & P-Value $\leq \mathbf{0 . 0 5}$ & Significance \\
\hline Gender & 2.990 & 1 & 0.084 & N.S \\
\hline Age & 4.988 & 4 & 0.289 & N.S \\
\hline Qualification & 2.111 & 3 & 0.550 & \\
\hline Marital Status & 0.660 & 1 & 0.416 & N.S \\
\hline Years of Clinical experience & 2.469 & 1 & 0.116 & N.S \\
\hline Years of Psychiatric experience & 1.451 & 1 & 0.228 & N.S \\
\hline
\end{tabular}

d.f: degree of freedom, P: Probability, N.S: Not significant

This table presents the relationships between nurses knowledge about legal issues with their demographic characteristics; the table shows that there are no significant relationships between nurses' knowledge with their demographic characteristics of gender, age, qualification, marital status, and years of experience at $\mathrm{p}$-value $\leq 0.05$.

Table (5) The Relationship between Nurses' Knowledge about Ethical Issues with their Socio-demographic Characteristics $(\mathrm{N}=100)$

\begin{tabular}{|c|c|c|c|c|}
\hline $\begin{array}{ll}\text { Characteristics } & \text { Knowledge } \\
\end{array}$ & Chi-square & d.f & P-Value $\leq 0.05$ & Significance \\
\hline Gender & 0.883 & 1 & 0.347 & N.S \\
\hline Age & 2.812 & 4 & 0.580 & N.S \\
\hline Marital Status & 0.094 & 1 & 0.759 & N.S \\
\hline Years of Clinical experience & 1.741 & 1 & 0.187 & N.S \\
\hline Years of Psychiatric experience & 2.052 & 1 & 0.152 & N.S \\
\hline
\end{tabular}

d.f: degree of freedom, P: Probability, N.S: Not significant, S: Significant

This table presents the relationships between nurses knowledge about ethical issues with their demographic characteristics; the table shows reports that no significant relationships have been reported between nurses' knowledge with their demographic characteristics of gender, age, qualification, marital status, and years of experience at $\mathrm{p}$-value $\leq 0.05$.

\section{Discussion}

The analysis of finding in table (1) reported that the majority of psychiatric nurses were female nurses, the finding related to nurses' gender can be explained that nursing profession is widely accepted between women more than men, it is also considered as a women's profession, another explanation that of most of nursing schools are graduate female nurses only. The finding reported that dominant age group of the nurses was between twenties and thirties, who were married with and graduated from nursing school, the dominant age among nurses refers to the newly recruited nurses in this field, in addition to the desire of young people to get a job, especially, nursing appointment is a central by Ministry of Health, and also that nursing school are graduate a young nurses as mentioned above. Regarding marital status of nurses, the researchers see that young people are willing for early marriage, having a family, and settle down explain why most of the nurses are married. The findings of this study are supported by the findings of Zaki ${ }^{(5)}$ who found similar findings in her study.

Because nursing schools are more available and accessible, many students are prefer to engage in those school as a short way in which they can graduated and got a job, therefore, the nurses under this study have been shown with nursing school qualification (Table 1). The finding of the clinical experience years in psychiatric revealed that nurses have more than five years of clinical experience especially, in the psychiatric nursing, this can be interpreted by nurses have not interested in such field and they been employed in different departments and been transferred lately to the psychiatric hospital. A study presents a supportive evidenced for this study that 
found Mohammed ${ }^{(6)}$. The table (1) also found that a small number of nurses have reviewed the Iraq Mental Health Act, this may be explained by the larger number of the nurses in this study have less than five years in the psychiatric field and also due to the poor interest in related trends and issues in the field. The findings above were disapproved with findings of Mohammed $^{(6)}$ that found different results.

The finding of table (2) revealed that a large number of psychiatric nurses have a good knowledge about legal issues in mental health nursing; this may be explained by the increasing role of the nurse as a patient care taker and advocate, and to avoid the mistakes that have negative consequences. So the nurse must be aware about the legal issues of nursing profession in order to avoid these legal problems. Another explanation for such finding that lack of governmental affairs in protecting the rights of working nurses during critical situations in which they might exposed to workplace violence. These finding were disagreed with findings of Kumar and his colleagues ${ }^{(7)}$ who concluded that nurses have a poor knowledge on the laws of the profession and the legal issues.

It has known of the finding in table (3) that most of the nurses are showing a good level of knowledge about ethical issues in mental health nursing, and the staff working in mental health hospitals have reviewed the code of ethics (table 1), this means that nurses are aware of the code of ethics as a part of their duty's responsibilities; good knowledge is to be considered in different training courses and lectures about ethical issues in their work-place. A supportive evidence for this study has been found Mohajjel- Aghdam et al. ${ }^{(8)}$ and this finding was disapproved by Hariharan et al., ${ }^{(9)}$ that found different result.

The finding of table $(4,5)$ shows that there is no significant relationship between nurses' knowledge about legal and ethical issues respect to their demographic characteristics of age, gender, qualification, martial status and years of experience, such findings may be interpreted by the results in table (1) in which the nurses under this study were young with low experience in their field, on the other hand, their good knowledge about these aspect is also considered as an important factor in interpretation of this not significant relationships. The finding is supported by the finding of Kumar et al., ${ }^{(3)}$ who also concluded that there is no significant association found between nursing knowledge with their demographic characteristics, while the finding of this study was disagreed with the study of Hameed ${ }^{(10)}$ who concluded that there is a significant relationship between them.

\section{Conclusions}

(1) Most of the nurses how are working at psychiatric wards were female with age 20-30 years old and graduated from medical institute.

(2) The nurses have more than five years of experience in nursing and psychiatric nursing and working at wards.

(3) The nurses have good knowledge about legal and ethical issues in mental health nursing.

(4) There is no significant relationship between nurses' with respect to their age, gender, qualification, marital status and years of experience.

\section{Recommendations}

(1) Provide training courses for nurses who are working at psychiatric units to increase their practices about ethical and legal issues in such setting.

(2) The booklet of "Legal and Ethical Issues in Mental Health Nursing" should be distributed for newly recruited nurses in psychiatric hospitals and wards.

\section{References}

[1] World Health Organization, (2009), Code of Ethics for Nurses and Midwives in Iraq.

[2] American Nurse Association, (2010), Nursing: Scope and Standards of Practice, $2^{\text {nd }}$ ed., Silver Spring.

[3] Kumar, R., Mehta, S., Kalra, R., (2011), Knowledge of Staff Nurses Regarding Legal and Ethical Responsibilities in the Field of Psychiatric Nursing, Nursing and Midwifery Research Journal, 7(1), pp: 1-2.

[4] Shrestha, S., Jose, P., (2014), Knowledge and Practice of Nursing Ethics and Laws , Journal of Universal Collage of Medical Sciences, 2(3),p.31.

[5] Zaki, R. (2016), Job Stress and Self-Efficacy among Psychiatric Nursing Working in Mental Health Hospitals at Cairo, Egypt, Journal of Education and Practice, 7(20), pp. 103-113.

[6] Mohammed, Q. (2015). Nurses Attitudes toward Using of Patients Physical Restraint at Psychiatric Hospital in Baghdad, Kufa Journal for Nursing Sciences, 5(3), pp. 105-112.

[7] Kumar, H., Jain, K., and Mathur, D. R, (2013), Legal Awareness and Responsibilities of Nursing Staff in Administration of Patient Care in a Trust Hospital, Retrieved from https://www.ncbi.nlm.nih.gov/pmc/articles/pmc3919375/\#!po=81.4516 , accessed by April $21,2017$.

[8] Mohajjel-Aghdam, A., Hassankani, H., and Moghaddam, S., (2013), Knowledge and Performance about Nursing Ethic Codes from Nurses and Patients Perspective in Tabriz Teaching Hospitals, Retrieved from https://www.ncbi.nlm.nih.gov/pmc/articles/pmc4134161/\#!po=0.781250, accessed by April 21, 2017.

[9] Hariharan, S., Jonnalagadda,R., Walrond, E., and Moseley ,H, (2006), Knowledge, Attitudes and Practice of Health Care Ethics and Laws among Doctors and Nurses in Barbados, BMC Med Ethics, 7(7), pp. 230-239.

[10] Hameed, D. (2013), The Knowledge of Students in Nursing College about Nursing Process, Kufa Journal for Nursing Sciences, 3(1), p.184. 